\title{
The Operation Mechanism of Amoeba's Organizational Model
}

\author{
Fangze Yang \\ Jinan University, Guangzhou, China \\ Email: yfzjnu@163.com
}

How to cite this paper: Yang, F.Z. (2018) The Operation Mechanism of Amoeba's Organizational Model. Open Journal of Business and Management, 6, 462-469. https://doi.org/10.4236/ojbm.2018.62034

Received: August 3, 2017

Accepted: April 27, 2018

Published: April 30, 2018

Copyright $\odot 2018$ by author and Scientific Research Publishing Inc. This work is licensed under the Creative Commons Attribution International License (CC BY 4.0).

http://creativecommons.org/licenses/by/4.0/ (c) (i) Open Access

\begin{abstract}
In recent years, there has been an upsurge of researching and learning the Amoeba management model in China. Amoeba management model is a business model created by INAMORI KAZUO in KYOCERA, and then many enterprises have achieved unprecedented success. At present, a large number of scholars have studied the amoeba management model, but the exploration of the operation mechanism of the amoeba management model has not yet appeared. As for an organization management model, it is very important to explore the mechanism for its normal operation, which provides the research question for this article, namely, the operation mechanism of amoeba organization model. Therefore, based on the characteristics of Amoeba organization, this paper explores the operation mechanism of Amoeba's organizational model, which provides reference for other enterprises that want to implement the Amoeba organization model. The research found that the operation mechanism of Amoeba's organizational model mainly includes Amoeba's team relationship, team incentive mechanism, team accounting mechanism and team evaluation mechanism. The Amoeba team broke the traditional relationship between the corporate sector and the traditional relationship resulting in low efficiency of the enterprise, while the amoeba organization leads the trading relationship into the enterprise Amoeba teams, the trading between teams, and self-financing of each team resulting in the active communication between teams and the actively cooperate. The Incentive mechanism is mainly for the amoeba team decentralization, the establishment of a strict responsibility and profit mechanism for each team, the division of power and responsibility, so that each team has its own power. The accounting mechanism and the accounting of Amoeba organization model mainly introduce the independent accounting mechanism; each team is responsible for its own profit and loss, independent accounting, and uses the unit time accounting system to calculate the team. The Evaluation mechanism rigorously assesses the amoeba team. In the light of the strategy at this stage of the company, we need
\end{abstract}


to build a guiding evaluation system so that the team goals and corporate goals become same, and commonly achieve the enterprise strategies.

\section{Keywords}

Amoeba Organization Model, Mechanism, Operation Mechanism

\section{Introduction}

\subsection{Research Problem}

With the advent of the Internet era, enterprises are facing the needs of consumers personalized, the problem of information asymmetry between enterprises and users has gradually disappeared, users can quickly compare the products needed through the Internet, and the initiative of information is in the hands of the users. To quickly meet the individual needs of consumers, companies need to respond quickly. In addition, with the development of enterprises, enterprises are getting bigger and bigger; there will be more and more problems such as the level of high, low efficiency of communication, which naturally led the enterprise difficult to quickly meet consumer demand.

Because of the need to change the traditional organizational model to meet the rapid changes in the needs of consumers, INAMORI KAZUO founded the operation of amoeba in the Kyocera Company, which is divided into thousands of amoeba, the general twelve or three for an amoeba. Each amoeba members have to participate in their own amoeba group. Each amoeba production and management accounting is as a whole, and each amoeba group can be split and combined between the arbitrary, making the company to make a soft and rapid response to the market changes [1].

Compared with the project team in modern enterprises, there are distinct characteristics of amoeba business: Firstly, we should attach importance to the profits created by the manufacturing sector, and realize the empowerment and profit sinking. INAMORI KAZUO divided KYOCERA's manufacturing division into thousands of independent accounting and autonomous Amoeba [2]. The implementation of independent accounting and cost control is to empower the responsibility and authority assigned to the grass-roots units and members. Grassroots members will no longer be simply managed, they also have the participation, cost control and profit management. The entire manufacturing sector and even the company's profits came from the sum of the profits of the various amoebas.

Second characteristic is based on the unit time accounting system, so that employees in Amoeba know the market price changes and their effects on their work in time. Accurately, and actively control the cost according to the market demand. Amoeba management relies on unit time accounting system to realize cost control [3]. 
In recent years, there has been a boom in the study and study of amoeba's business model. Amoeba is a business model created by Koizumi Kazuo in Kyocera, and has won unprecedented success in many companies. At present, there are a large number of scholars on the amoeba business model research, but to explore the operation mechanism of the amoeba organization model research has not yet appeared, and for an organization business model, to explore its normal operation mechanism is essential, Which provides a research for this article, that is, the study of the operation mechanism of amoeba tissue model.

So what is the operating mechanism of the amoeba business model? This paper argues that the operating mechanism of the amoeba business model includes: the relationship between the teams, the incentive mechanism, the accounting mechanism and the evaluation mechanism.

\subsection{Significance}

\subsubsection{Theoretical Significance}

Previous studies on the organization model of amoeba have remained at the one-sided perspective. Some studies have studied the accounting system from the accounting system of amoeba, and some studies have studied the incentive mechanism. The degree of operation can be explained that the operation mechanism of the amoeba organization model, but not comprehensive. The mechanism of inquiry, has a deep theoretical significance, from a broader perspective on the amoeba organization model.

\subsubsection{Practical Significance}

Now a lot of enterprises are in the study of amoeba organization model, it is difficult to let this kind of organizational model landed, so this article through the operation of the amoeba organization model to study, from the mechanism level to the enterprise to inspire, enterprises which are in the change Organization model can make reform from the team relationship, accounting mechanism, incentive mechanism and evaluation mechanism of the four aspects of the enterprise amoeba organization model design. Therefore, the research of this paper can better guide the implementation of the enterprise amoeba organization model.

\section{Operation Mechanism of Amoeba Organization Model}

\subsection{The Relationship among the Amoeba Teams}

The amoeba organizational management mode is that the enterprise employees are all in the Amoeba teams, which breaking the previous model that the enterprise organization model exists with department as boundary [2]. Between the teams there exists transaction, leading the external transaction into enterprise to form the internal market.

The traditional mode of enterprise organization, the employees in different departments need to communicate each, in the enterprise business, because of 
the low efficiency of cross departmental communication, which cause the efficiency of conventional organization mode is pretty low. What's worse, many times there is a serious rift among the sectors. For example, when the design department need to design products, there is need for cooperation with the sale department and production department, which requires cross department communication, and in the communication process, there will be such problems [4].

The organizational model of Amoeba's team form is that employees exist in different teams, and teams need to communicate each other. Thus, the amoeba organization leads the trading rules into the teams. That is, the relationship between different departments is no longer traditional but replaced by internal exchanges. For example, Between manufacturing and functional departments, the manufacturing sector needs the human resources department helping to recruit new employees, in the traditional relationship, for the human resources department, although the recruitment is in the mission of the department, but there is no mandatory assessment of this demand, so the human resources department may appear slack. Let's see the new relationship between the teams, manufacturing team and human resources team, when the manufacturing team need to hire new employees, they will sign the contract with the human resources team. Income can only be obtained by finishing work, That is, the human resources department will accept the performance evaluation by the manufacturing department. Thus, the human resources department will certainly try its best to do human resource management for each department for its own benefit. What's more, the quantity and quality of the employees directly affect the performance of the HR Department because the former relationship does no longer exist, instead of market trading relationship [4].

The leading of inside transaction into enterprise can let each team full of passion, when a monk knocked one day the bell man will no longer exist. Nothing will be won without effort will become a reality, so the relationships among the teams, greatly stimulated the dynamic amoeba organization.

\subsection{Incentive Mechanism}

Constructing the Incentive mechanisms, which are matching with the small units. There are many kinds of incentives in the enterprise human resource management, while the most basic way is the material incentive based on the principle of "benefit driven". Because of the limited rational "economic man", the first thing to consider is the "economic factors"; secondly, the currency is the standard of value function, material incentives can be regarded as the recognition of the value of the enterprise employees, satisfy the employee's sense of achievement [5].

Therefore, material incentive is still the basic way of motivating human resources in modern enterprises. Salary incentive is the most basic way of material incentive, so the establishment of a perfect salary system is the basic requirement of effective incentive for employees. 
The salary system of small business units is mainly based on project output value and contribution, supplemented by post coefficient, and the company's unified performance distribution system promotes internal flow and internal cooperation of personnel. The establishment of project cost and artificial employee role evaluation standard, performance and position decoupling, according to the project contribution and role performance contribution, which can achieve hard work and can work more.

In amoeba, functional managers' performance is linked to frontline production performance. The traditional incentive mechanism may be much more for business units-front-line staff, the implementation way of basic salary plus the commission to motivate employees to work hard, and the functional departments of the employees may not find appropriate assessment methods, which result in part of the function of staff work slackly. While the company is a large system, some departments are not high enthusiasm, it will affect the efficiency of the entire company's business development, so the kind of cross organizational structure has become increasingly difficult to adapt to the current development of enterprises. For amoeba structure, any department teams have their own incentive mechanism, and for the functional department, form a trading relationship with the team of other business units. For example, the human resources department is composed of the Amoeba team, in the signing of contracts with the manufacturing sector, the manufacturing sector for the quarter clear need to recruit 2 executives, so for the human resources department, It needs to complete the goal, otherwise, the manufacturing sector will not pay for the human resources department.

The salaries of the functional departments are linked to the performance of their work, at the same time linked to the front-line staff work performance, which can fully motivate the various departments to work hard.

\subsection{Accounting Mechanism}

In pursuit of maximum revenue, cost minimization and profit maximization, the Amoeba organization's business accounting methods are consistent with the traditional financial management objectives. The unique nature of its process management lies in its independent operation and accounting, such as refinement of organizational units, independent accounting and internal mutual transactions. Accounting methods can be divided into internal and external transactions. The internal transactions are usually generated in the enterprise internal departments and business departments, functional departments do not directly generate profits They provide support to the business department by providing products, services or security, such as the enterprise internal management department and customer service department, the income of the department in the internal source is from other "Amoeba" unit in the enterprise. Forms of insider trading and clearing work order, acceptance of products and services of the "Amoeba" unit is built for the corresponding expenditure, the two 
sides formed internal transaction relationship [6].

Generally speaking, external trading is the normal operation and sales activities of an enterprise. Through signing contracts with external units or individuals, it confirms the income, and the corresponding economic benefits go directly to the enterprise. Once all the amoeba units within the enterprise have a profit-oriented business principle. In their respective business segments, they should strive for maximum sales revenue, and at the same time they should try to reduce costs, and constantly increase the actual profits, enterprises will naturally achieve high returns.

Therefore, before formulating the accounting plan for the amoeba team, it is necessary to determine the principles for the collection and allocation of the company's revenues, costs and expenses. The specific principles are as follows:

Firstly, according to the principle of "paid use, who uses, who benefits, who is responsible", the cost is included and apportioned.

Secondly, according to the "one-to-one correspondence" principle, the income and cost, expenses matching in the same period.

Thirdly, according to the "occurrence system" and "cash based management" principle, the required goods are bought with the procurement of goods, all included in operating costs in the procurement, accounting in the table to reflect the business activities of capital flows, as far as possible to eliminate or show the difference between accounting profit and implementation cash profit. When the performance of the service or sales is completed, it is included in the operating income, the non-receivable is included in the accounts receivable, and the cost of the capital is calculated. In the accounting table, it accurately reflects the capital flow of the business activities of the month, and can eliminate or show the difference between the accounting profit and the cash profit.

The method in the establishment of accounting mechanism mainly uses the amoeba team added value per unit time; the added value per unit time is an important index for the performance of accounting unit amoeba. It is said that the team can create additional value in an hour, equal to the accounting period operating income — the business cost—the operation cost—cost of capital—management fee allocation. The balance divided the amoeba' (including support staff members seconded) working time (hours). If the added value of the unit time is greater than the company's per hour per capita income expenditure. It shows that the amoeba team achieves the goal.

\subsection{Evaluation Mechanism}

The business team evaluation mechanism means with control objectives or performance standards, using the evaluation methods of the development assessment to see if the team has completed the task, team work and team responsibilities, and reflecting the evaluation result to the system of business team. With the arrival of the era of knowledge economy and the deepening of the process of global economic integration, enterprises are faced with a changing living envi- 
ronment and fierce competition. It can be said that the establishment and improvement of enterprise performance appraisal system is related to the improvement of staff performance and the rapid development of enterprises [7].

In the amoeba management system, in the strict sense, there is no real performance appraisal. The core objective of Amoeba's organization is to make the enterprise internal business unit staff to better understand their business and focus on the business sector, and actively in the management to find problems, solve problems, rather than let the employee bonus and positively related to team performance. It is a tool for performance and management improvement rather than short-term performance improvement. It belongs to the personnel training mechanism rather than the bonus management and profit sharing performance management model.

For the amoeba team evaluation, mainly for performance indicators evaluation, that is, work ability indicators. Besides, the assessment cycle is divided into monthly assessment, quarterly assessment and annual assessment.

\section{The Conclusions of the Study}

In this paper, the operation mechanism of amoeba organization model is studied, and it is concluded that the organization should implement the amoeba organization model, starting from the four aspects of team relationship establishment, accounting mechanism, incentive mechanism and evaluation mechanism.

Enterprises in the implementation of amoeba organization model need to follow certain rules, and according to the results of this study, that is: First establish the basic organizational unit of the enterprise and the relationship between the Amoeba team. According to the actual situation of enterprises, enterprises establish contractual relationship between teams, introducing the market mechanism into the enterprise, and clearing the team in accordance with the market relationship; followed by the design of the corresponding accounting mechanism, where the accounting mechanism is mainly on the team's self-financing and accounting team. Third, the incentive system can be divided into material incentives and non-material incentives, because the relationship between team and business is self-financing. The design of the incentive mechanism should be based on this Characteristics; Finally, the design of the evaluation mechanism of the enterprise team, mainly based on performance as a basis for evaluation, making the team goals and business goals to be the same.

In addition, due to the design of the enterprise amoeba organization model, mainly from the above four aspects of the design, and the four aspects in the actual operation of the need for information system-based tools, only the information system as a basic tool can make the transactions between the various teams within the enterprise be successfully completed. The accounting and evaluation of each team can be completed with high efficiency, which is precise because the development of Internet technology makes it possible to introduce market me- 
chanism within the enterprise [8].

\section{Research Limitations and Prospects}

Based on the study of the operation mechanism of amoeba organization model, this paper concludes that the implementation of the amoeba organization model should start from the four aspects of team relationship establishment, accounting mechanism, incentive mechanism and evaluation mechanism, and highlights the enterprise information system The importance of the amoeba organization model is smooth, but there are still the following shortcomings: First of all, this article in the study of the operating mechanism, mainly through the combing of various types of literature to draw the conclusion, combined with the definition of operating mechanism of the operation of the amoeba mode of operation of the four categories, to a certain extent, out of the enterprise, So it may be biased with the actual situation.

Secondly, the research results of the operation mechanism are simply described, and the steps or techniques of the actual operation of the enterprise are not studied, which may cause inconvenience in practical application.

In the future, we hope that we can take the example of the business model of the amoeba organization model (Kyocera best), take the rooting theory to take the root of the collected enterprise data, take the operation mechanism of the amoeba organization model, form new theory, Theory derived from the data, more convincing.

\section{References}

[1] Mullender, S.J. (1987) The Amoeba Distributed Operating System. Centrum voor Wiskunde en Informatica, Amsterdam, 309.

[2] Kazuo, I. and Cao, X.Y., Trans. (2018) Amoeba Operating. Management of State-Owned Enterprises (Oil Manager), No. 1.

[3] Chun, L.L. (2017) Research Based on Amoeba Management Model. Enterprise Reform and Management, No. 20, 102.

[4] Helias, S.E. (2012) Amoeba (Operating System). Rupt, 2012.

[5] Kazuo, I. (2017) Inamori Kazuo Amoeba Operation. Global Business Classics, No. 5,159 .

[6] Tanenbaum, A.S., Kaashoek, M.F., van Renesse, R. and Bal, H.E. (1991) The Amoeba Distributed Operating System-A Status Report. Computer Communications, 14, 324-335. https://doi.org/10.1016/0140-3664(91)90058-9

[7] Tanenbaum, A.S., Renesse, R.V., Staveren, J., et al. (1990) Experience with the Amoeba Distributed Operating System. Communications of the ACM, 19, 223-234. https://doi.org/10.1145/96267.96281

[8] Leinartas, E.K. (2011) Stability of the Cauchy problem for a Multidimensional Difference Operator and the Amoeba of the Characteristic Set. Sibirskii Matematicheskii Zhurnal, No. 5, 1087-1095. 